\title{
Analisis Pengaruh Prestasi Pengajaran Mikro dan Kemampuan Disposisi Matematika terhadap Kemampuan Mengajar Matematika dalam Program Pengalaman Lapangan (PPL)
}

\author{
Sofri Rizka Amalia ${ }^{1}$, Dian purwaningsih ${ }^{2}$ \\ Program Studi Pendidikan Matematika, Universitas Peradaban Bumiayu \\ Email : sofri.rizkia@gmail.com ${ }^{1}$,dian.purwaningsih24@yahoo.com ${ }^{2}$
}

\begin{abstract}
ABSTRAK
Penelitian ini bertujuan untuk menganalisis pengaruh prestasi pengajaran mikro terhadap kemampuan mengajar matematika dalam PPL, menganalisis pengaruh kemampuan disposisi matematika terhadap kemampuan mengajar matematika dalam PPL, dan menganalisis pengaruh prestasi pengajaran mikro dan kemampuan disposisi matematika terhadap kemampuan mengajar matematika dalam PPL. Populasi dalam penelitian ini adalah mahasiswa pendidikan matematika Universitas Pancasakti Tegal dan UNiversitas Peradaban Bumiayu. Pengambilan subjeknya dengan purposive sampling. Subjek dalm penelitian ini adalah mahasiswa semester VIII program studi pendidikan matematika Universtas Peradaban Bumiayu, dan Universitas Pancasakti Tegal. Analisis dalam penelitian ini dengan uji regresi menggunakan SPSS 16. Hasil analisis penelitian ini adalah ada pengaruh positif prestasi pengajaran mikro terhadap kemampuan mengajar matematika dalam PPL, ada pengaruh positif kemampuan disposisi matematika terhadap kemampuan mengajar matematika dalam PPL, ada pengaruh positif prestasi pengajaran mikro dan kemampuan disposisi matematika terhadap kemampuan mengajar matematika dalam PPL.
\end{abstract}

Kata kunci : Pengajaran mikro, disposisi matematika, mengajar matematika dalam PPL

\section{PENDAHULUAN}

Sumber daya manusia yang berkualitas merupakan modal dasar dalam persaingan di era globalisasi sekarang ini. Guru dipandang sebagai faktor kunci, karena guru berinteraksi secara langsung dengan muridnya dalam proses belajar mengajar. Lembaga Pendidik Tenaga Kependidikan (LPTK) yang selama ini diberi kewenangan mempersiapkan guru dipandang sebagai lembaga yang paling bertanggung jawab terhadap kualitas pendidikan.

Kemampuan mengajar mahasiswa Program Pengalaman Lapangan (PPL) merupakan salah satu tolak ukur kualitas calon seorang guru. Akan tetapi, sebagian besar kemampuan mengajar mahasiswa masih rendah. Hal ini sesuai dengan hasil observasi dan wawanca pada beberapa sekolah tempat PPL dan LPTK yang mengadakan PPL. Menurut Puspita dalam Arsito (2014), program Pengalaman Lapangan (PPL) adalah salah satu kegiatan kurikuler yang merupakan kaliminasi dari 
seluruh program pendidikan yang telah dihayati dan dialami mahasiswa di LPTK untuk menerapkan berbagai pengetahuan, sikap, dan ketrampilan dalam rangka pembentukan guru yang profesional yang dirancang khusus untuk menyiapkan para calon guru menguasai kemampuan keguruan yang terintegrasi dan utuh, sehingga setelah menyelesaikan pendidikannya dan diangkat menjadi guru, mereka siap mengemban tugas dan tanggung jawab sebagai guru. Kemampuan mengajar matematika dalam Program Pengalaman Lapangan (PPL) adalah kemampuan mahasiswa calon guru menerapkan berbagai ketrampilan mengajar dalam menyampaikan materi matematika yang meliputi ketrampilan menyusun rencana pengajaran, ketrampilan melaksanakan prosedur mengajar dan ketrampilan mengadakan evaluasi dalam Program Pengalaman Lapangan (PPL) agar kegiatan belajar mengajar yang dilaksanakan dapat berhasil sehingga terjadi pembentukan kemampuan profesional mahasiswa calon guru.

Adapun faktor-faktor yang mempengaruhi kemampuan mengajar dalam PPL adalah pengajaran mikro. Dalam pengajaran mikro, mahasiswa kurang aktif, dan tidak memanfaatkan kesempatan untuk melatik kemampuan mengajarnya. Saat pengajaran mikro mahasiswa kurang percayaan diri, tidak ingin tahu kekurangan yang dimiliki, tidak melakukan refleksi kemampuan yang dimiliki dan mengaplikasikan pengetahuannya saat pengajaran mikro, mahasiswa juga kurang mengapresiasi peran matematika dalam pembelajaran, mengeksplorasi ide-ide matematis dan mencoba metode alternatif dalam menyelesaikan masalah.

Menurut Supriatna (2009), menyebutkan bahwa pengajaran mikro merupakan suatu sistem yang memungkinkan seorang calon guru mengembangkan ketrampilannya dalam menerapkan teknik mengajar tertentu. Pengajaran mikro diuraikan sebagai suatu sistem kawalan praktis dengan tumpuan kepada tingkah laku pengajaran yang khusus dan berlatih supaya mengajar dalam situasi yang terkawal (Allen dan Eve, 1968).

Dalam bahan ajarnya, Supriatna (2009) menyebutkan komponen ketrampilan mengajar meliputi: (1) ketrampilan membuka dan menutup pelajaran, (2) ketrampilan menjelaskan, (3) ketrampilan memberi penguatan, (4) ketrampilan bertanya, (5) ketrampilan memberi variasi, (6) ketrampilan menggunakan media pelajaran, (7) ketrampilan membimbing diskusi kelompok kecil, (8) ketrampilan mengelola kelas.

Mahasiswa calon guru harus memulainya dengan berlatih ketrampilan mengajar secara terisolasi dalam pengajaran mikro. Di samping itu, perlu mendorong dan membantu mahasiswa agar tekun, percaya diri, pantang menyerah, dan melakukan refleksi terhadap kemampuan mengajar matematika yang telah dilakukannya, sehingga tumbuh sikap atau disposisi positif terhadap matematika dalam diri mahasiswa. National Council of Teacher Mathematic (NCTM, 2003) menetapkan ada 7 (tujuh) standar proses yang harus dikuasai calon guru matematika, yaitu : (1) Knowledge of Mathematical Problem Solving; (2) Knowledge of Reasoning and Proof; (3) Knowledge of Mathematical Communication; (4) 
Knowledge of Mathematical Connections; (5) Knowledge of Mathematical Representation; (6) Knowledge of Technology; (7) Dispositions.

Menurut NCTM (1989) Siswa belajar matematika melalui konsep, prosedur, dan aplikasi. Hal ini juga mencakup pengembangan disposisi terhadap matematika dan bagaimana siswa melihat matematika sebagai salah satu cara untuk menyelesaikan suatu masalah. Disposisi merujuk bukan hanya untuk sikap tetapi kecenderungan untuk berpikir dan bertindak dengan cara yang positif. Sedangkan menurut NCTM (1989) dalam Mahmudi (2010) disposisi matematis mencakup beberapa komponen sebagai berikut:

1) Percaya diri dalam menggunakan matematika untuk menyelesaikan masalah, mengkomunikasikan ide-ide matematis, dan memberikan argumentasi.

2) Berpikir fleksibel dalam mengeksplorasi ide-ide matematis dan mencoba metode alternatif dalam menyelesaikan masalah.

3) Gigih dalam mengerjakan tugas matematika.

4) Berminat, memiliki keingintahuan (curiosity), dan memiliki daya cipta (inventiveness) dalam aktivitas bermatematika.

5) Memonitor dan merefleksi pemikiran dan kinerja.

6) Menghargai aplikasi matematika pada disiplin ilmu lain atau dalam kehidupan sehari-hari.

7) Mengapresiasi peran matematika sebagai alat dan sebagai bahasa.

Menurut Bondan dalam Sofuroh (2014), disposisi produktif berkaitan dengan kecenderungan untuk mempunyai kebiasaan yang produktif, untuk melihat matematika sebagai hal yang masuk akal, berguna, bermakna, dan berharga, dan memiliki kepercayaan diri dan ketekunan dalam belajar/bekerja dengan matematika. Dengan kemampuan pengajaran matematika dan disposisi positif diharapkan siswa mampu meraih prestasi kemampuan mengajar matemtaika dalam PPL. kemampuan pengajaran matematika dan disposisipositif diharapkan siswa mampu meraih prestasi kemampuan mengajar matemtaika dalam PPL.

\section{METODE PENELITIAN}

Penelitian ini berjenis kausal yaitu tipe penelitian yang bersifat konklusif, bertujuan menjelaskan pengaruh antar variabel yang dibedakan menjadi variabel independent sebagai variabel penyebab dan variabel dependen sebagai variabel yang menjadi akibat dari sebuah fenomena.

Populasi dalam penelitian ini adalah mahasiswa jurusan pendidikan matematika Universitas Pancasakti Tegal dan Universitas Peradaban Bumiayu. Pengambilan subjeknya dengan purposive sampling. Subjek dalm penelitian ini adalah mahasiswa semester VIII program studi pendidikan matematika Universtas Peradaban Bumiayu, dan Universitas Pancasakti Tegal. Kelas VIII B Universitas Pancasakti Tegal (UPS) sebagai kelas uji coba, kelas VIII A, VIII C, VIII D UPS dan PMAT VIII Universitas Peradaban (UP) sebagai Responden. 
Teknik yang digunakan adalah (1) kuesioner digunakan untuk mengumpulkan data atau mendapatkan data kemampuan disposisi matematika mahasiswa, (2) Wawancara ini digunakan untuk membantu peneliti dalam mendapatkan data mengenai pengaruh antar variabel secara mendalam dari tiga kelompok yaitu subjek kelas atas, tengah, dan bawah, (3) dokumentasi untuk memperoleh data mahasiswa. Analisis data penelitian ini dengan menggunakan SPSS 16 yaitu uji regresi.

\section{HASIL DAN PEMBAHASAN}

1. Uji pengaruh prestasi pengajaran mikro $\left(X_{1}\right)$ terhadap variabel kemampuan mengajar matematika dalam PPL a $(Y)$.

Hipotesisnya adalah :

$H_{0}: \beta_{1}=0 \quad$ (Tidak ada pengaruh linier prestasi pengajaran mikro terhadap kemampuan mengajar matematika dalam PPL mahasiswa)

$H_{1}: \beta_{1} \neq 0$ (Ada pengaruh linier prestasi pengajaran mikro terhadap kemampuan mengajar matematika dalam PPL mahasiswa)

Dalam penelitian ini perhitungan menggunakan program SPSS. Hasilnya dapat dilihat pada Tabel 1.

Tabel 1. Output Anova Regresi $X_{1}$ Terhadap $Y$

\begin{tabular}{lrrrrr}
\hline \multicolumn{1}{c}{ Model } & Sum of Squares & df & Mean Square & F & Sig. \\
\hline 1Regression & 1078.348 & 1 & 1078.348 & 120.343 & $.000^{\mathrm{a}}$ \\
Residual & 958.790 & 107 & 8.961 & & \\
Total & 2037.138 & 108 & & & \\
\hline
\end{tabular}

a. Predictors: (Constant), Microteaching

b. Dependent Variable: PPL

Tabel 1. di atas diperoleh nilai $F=120,343$ dan nilai signifikannya adalah $0,000=0 \%<5 \%$ yang berarti $H_{0}$ ditolak. Hal ini berarti bahwa terdapat pengaruh linier yang signifikan prestasi pengajaran mikro terhadap kemampuan mengajar matematika dalam PPL mahasiswa. Koefisien regresi terlihat pada Tabel 2.

Tabel 2. Output Coefficients Persamaan Regresi $X_{1}$ Terhadap $Y$

\begin{tabular}{ccccccc}
\hline \multirow{2}{*}{ Model } & \multicolumn{2}{c}{$\begin{array}{c}\text { Unstandardized } \\
\text { Coefficients }\end{array}$} & $\begin{array}{c}\text { Standardized } \\
\text { Coefficients }\end{array}$ & & \\
\cline { 2 - 5 } & $\mathrm{B}$ & Std. Error & Beta & & t & Sig. \\
\hline 1 (Constant $)$ & 29.988 & 4.889 & & & 6.133 & .000 \\
& & & & & &
\end{tabular}




\begin{tabular}{llllll} 
Microteaching & .674 & .061 & .728 & 10.970 & .000 \\
\hline
\end{tabular}

a. Dependent Variable: PPL

Dari Tabel 2 diketahui nilai $a=29,988, b=0,674$ sehingga diperoleh persamaan regrasi $\hat{Y}=29,988+0,674 X_{1}$. Ini berarti setiap penambahan variabel prestasi pengajaran mikro $\left(X_{1}\right)$ sebesar satu satuan maka akan menambah nilai kemampuan mengajar matematika dalam PPL(Y) sebesar 0,674. Terlihat tanda koefisien regresi positif, sehingga prestasi pengajaran mikro berpengaruh positif terhadap kemampuan mengajar matematika dalam PPL. Besarnya pengaruh dapat terlihat pada Tabel 3.

\begin{tabular}{ccccc}
\multicolumn{4}{c}{ Tabel 3. Output Model Summary $X_{1}$ Terhadap $Y$} \\
\hline Model & $\mathrm{R}$ & R Square & $\begin{array}{c}\text { Adjusted R } \\
\text { Square }\end{array}$ & $\begin{array}{c}\text { Std. Error of the } \\
\text { Estimate }\end{array}$ \\
\hline 1 & $.728^{\mathrm{a}}$ & .529 & .525 & 2.99344 \\
\hline
\end{tabular}

a. Predictors: (Constant), Microteaching

Dari Tabel 3 diperoleh nilai $R$ Square sebesar $0,529=52,9 \%$. Nilai tersebut menunjukan bahwa variabel prestasi pengajaran mikro mempengaruhi kemampuan mengajar matematika dalam PPL sebesar 52,9\% atau ada $47,1 \%$ dipengaruhi faktor lain.

\section{Uji Pengaruh Kemampuan Disposisi Matematika $\left(x_{2}\right)$ Terhadap kemampuan mengajar matematika dalam PPL ( $Y)$}

Hipotesis yang digunakan adalah:

$H_{0}: \beta_{2}=0$ (Tidak ada pengaruh linier kemampuan disposisi matematika terhadap kemampuan mengajar matematika dalam PPL mahasiswa)

$H_{1}: \beta_{2} \neq 0$ (Ada pengaruh linier kemampuan disposisi matematika terhadap kemampuan mengajar matematika dalam PPL mahasiswa)

Hasilnya dapat dilihat pada Tabel 4.

Tabel 4. Output Anova Regresi $X_{2}$ Terhadap $Y$

\begin{tabular}{ccccccc}
\hline \multicolumn{2}{c}{ Model } & $\begin{array}{c}\text { Sum of } \\
\text { Squares }\end{array}$ & df & $\begin{array}{c}\text { Mean } \\
\text { Square }\end{array}$ & F & Sig. \\
\hline \multirow{3}{*}{1} & Regression & 1509.390 & 1 & 1509.390 & 306.026 & $.000^{\mathrm{a}}$ \\
& Residual & 527.748 & 107 & 4.932 & & \\
\multicolumn{7}{l}{ a. Predictors: (Constant), K_Disposisi_Mat, b. Dependent Variable: PPL }
\end{tabular}


Tabel 4. di atas diperoleh nilai $F=306,026$ dan nilai signifikannya adalah $0,000=0 \%<5 \%$ yang berarti $H_{0}$ ditolak. Hal ini berarti bahwa terdapat pengaruh linier yang signifikan antara kemampuan disposisi matematika terhadap kemampuan mengajar matematika dalam PPL mahasiswa. Koefisien regresi terlihat pada Tabel 4.

Tabel 5. Output Coefficients Persamaan Regresi $X_{2}$ Terhadap $Y$

\begin{tabular}{|c|c|c|c|c|c|c|c|}
\hline \multirow{2}{*}{\multicolumn{2}{|c|}{ Model }} & \multicolumn{2}{|c|}{$\begin{array}{c}\text { Unstandardized } \\
\text { Coefficients }\end{array}$} & \multirow{2}{*}{\multicolumn{2}{|c|}{$\begin{array}{c}\begin{array}{c}\text { Standardized } \\
\text { Coefficients }\end{array} \\
\text { Beta }\end{array}$}} & \multirow[b]{2}{*}{$\mathrm{t}$} & \multirow[b]{2}{*}{ Sig. } \\
\hline & & B & Std. Error & & & & \\
\hline \multirow[t]{2}{*}{1} & (Constant) & -25.676 & 6.246 & & & -4.111 & .000 \\
\hline & K_Disposisi_Mat & .696 & .040 & & .861 & 17.494 & .000 \\
\hline
\end{tabular}

a. Dependent Variable: PPL

Dari Tabel 5. diketahui nilai $a=-25,676, b=0,696$ sehingga diperoleh persamaan regrasi $\hat{Y}=-25,676+0,696 X_{2}$. Terlihat tanda koefisien regresi positif, sehingga kemampuan disposisi matematika berpengaruh positif terhadap kemampuan mengajar matematika dalam PPL.

Tabel 6. Output Model Summary $X_{2}$ Terhadap $Y$

\begin{tabular}{lrrrr}
\hline Model & $\mathrm{R}$ & R Square & Adjusted R Square & $\begin{array}{c}\text { Std. Error of the } \\
\text { Estimate }\end{array}$ \\
\hline 1 & $.861^{\mathrm{a}}$ & .741 & .739 & 2.22086 \\
\hline a. Predictors: (Constant), K & Disposisi_Mat &
\end{tabular}

a. Predictors: (Constant), K_Disposisi_Mat

Dari Tabel 6. diperoleh nilai $\mathrm{R}$ Square sebesar $0,741=74,1 \%$. Nilai tersebut menunjukan bahwa variabel kemampuan disposisi matematika mempengaruhi kemampuan mengajar matematika dalam PPL sebesar $74,1 \%$ atau ada $25,9 \%$ dipengaruhi faktor lain.

3. Uji Pengaruh Prestasi Pengajaran Mikro $\left(X_{1}\right)$ dan Kemampuan Disposisi Matematika $\left(X_{2}\right)$ terhadap Kemampuan Mengajar Matematika dalam Program Pengalaman Lapangan (PPL) (Y).

Rumusan hipotesis :

$H_{0}: \beta=0$ (Tidak ada pengaruh linier pengaruh prestasi pengajaran micro dan kemampuan disposisi matematika terhadap kemampuan mengajar matematika dalam PPL mahasiswa) 
$H_{1}: \beta \neq 0$ (Ada pengaruh linier pengaruh prestasi pengajaran micro dan kemampuan disposisi matematika terhadap kemampuan mengajar matematika dalam PPL mahasiswa)

Hasilnya dapat dilihat pada Tabel 7.

Tabel 7.Output Anova Regresi $X_{1} \operatorname{dan} X_{2}$ Terhadap $Y$

\begin{tabular}{|l|r|r|r|r|r|}
\hline Model & Sum of Squares & df & Mean Square & F & \multicolumn{1}{c|}{ Sig. } \\
\hline $1 \quad$ Regression & 1589.636 & 2 & 794.818 & 188.26 & $.000 \mathrm{a}$ \\
& 447.501 & 106 & 4.222 & & \\
Residual & 2037.138 & 108 & & & \\
Total & & & & \\
\hline
\end{tabular}

a. Predictors: (Constant), Microteaching, K_Disposisi_Mat

b. Dependent Variable: PPL

Dari Tabel 7. diperoleh nilai $F=188,269$ dan nilai signifikannya adalah $0,000=0 \%<5 \%$. Disimpulkan bahwa ada pengaruh linier prestasi pengajaran micro dan kemampuan disposisi matematika terhadap kemampuan mengajar matematika dalam PPL.

Koefisien regresi terlihat pada Tabel 8.

Tabel 8. Output Coefficients Persamaan Regresi $X_{1}$ dan $X_{2}$ Terhadap $Y$

\begin{tabular}{llrrrrr}
\hline & & \multicolumn{2}{c}{ Unstandardized } \\
& \multicolumn{2}{c}{ Coefficients } & \multicolumn{2}{c}{$\begin{array}{c}\text { Standardized } \\
\text { Coefficients }\end{array}$} & & \\
\cline { 2 - 5 } Model & \multicolumn{1}{c}{ B } & Std. Error & Beta & \multicolumn{1}{c}{ t } & \multicolumn{1}{c}{ Sig. } \\
\hline 1 & (Constant) & -22.430 & 5.827 & & -3.850 & .000 \\
& K_Disposisi_Mat & .549 & .050 & .679 & 11.005 & .000 \\
& Microteaching & .249 & .057 & .269 & 4.360 & .000 \\
\hline
\end{tabular}

a. Dependent Variable: PPL

Terlihat pada Tabel 8 diketahui nilai $a=-22,430, b=0,549$, dan $c=0,249$. Bentuk persamaan regresinya adalah $\hat{Y}=-22,430+0,549 X_{1}+$ $0,249 X_{2}$.Terlihat tanda koefisien regresi positif, sehingga prestasi pengajaran micro dan kemampuan disposisi matematika berpengaruh positif terhadap kemampuan mengajar matematika mahasiswa dalam PPL.

Besarnya pengaruh pada Tabel 9. 
Tabel 9. Output Model Summary $X_{1} \operatorname{dan} X_{2}$ Terhadap $Y$

\begin{tabular}{lrrrr}
\hline Model & $\mathrm{R}$ & \multicolumn{2}{c}{$\begin{array}{c}\text { Adjusted R } \\
\text { Square }\end{array}$} & $\begin{array}{c}\text { Std. Error of the } \\
\text { Estimate }\end{array}$ \\
\hline 1 & $.883^{\mathrm{a}}$ & .780 & .776 & 2.05468 \\
\hline
\end{tabular}

a. Predictors: (Constant), Microteaching,_Disposisi_Mat

Dari Tabel 9. diperoleh nilai $\mathrm{R}$ Square $=0,780=78 \%$ nilai tersebut menunjukan bahwa variabel prestasi pengajaran micro dan kemampuan disposisi matematika secara bersama-sama mempengaruhi kemampuan mengajar matematika dalam PPL sebesar $78 \%$ masih ada $22 \%$ pengaruh faktor lain.

Setelah diperoleh data nilai mata kuliah microteaching yaitu prestasi pengajaran micro, maka dilakukan pengambilan subjek wawancara sejumlah 6 mahasiswa. Subjek wawancara terdiri dari 2 mahasiswa kelas atas, 2 mahasiswa kelas sedang, dan 2 mahasiswa kelas bawah. Hasil wawancara tentang pengaruh antar variabel adalah sebagai berikut.

Tabel 10. Hasil Wawancara Pengaruh Kemampuan Pengajaran Mikro terhadap Kemampuan Mengajar matematika dalam PPL.

\begin{tabular}{|c|c|}
\hline Subjek kelas & Pengajaran Mikro \\
\hline Atas & $\begin{array}{l}\text { a. Perencanaan dan model saat pengajaran mikro dapat menjadi } \\
\text { bekal saat PPL } \\
\text { b. Penguasann materi membuat mahasiswa siap dalam PPL } \\
\text { c. Akan tetapi ada kendala saat evaluasi, pembukaan, dan } \\
\text { penutupan pembelajaran lebih efektif ketika PPL }\end{array}$ \\
\hline Tengah & $\begin{array}{l}\text { a. Perencanaan dapat menjadikan pembelajaran saat PPL lebih } \\
\text { tetruktur, } \\
\text { b. Model pembelajaran saat pengajaran mikro memberikan } \\
\text { pengalaman mengatur waktu pembelajaran saat PPl dan sebagai } \\
\text { uji coba model yang efektif untuk PPL } \\
\text { c. Kendala yang terjadi adalah media saat PPL tidak tersedia } \\
\text { d. Saat pengajaran mikro hanya simulasi sehingga suasana dan } \\
\text { keadaan siswa saat PPL sangat berbeda }\end{array}$ \\
\hline Bawah & $\begin{array}{l}\text { a. Perencaan saat microteaching berpengaruh untuk mensiasati } \\
\text { kekurangan yang ada. tetapi ternyata saat PPL materi yang } \\
\text { diberikan tidak sesuai yang direncanakan. } \\
\text { b. Kemampuan membuka pembelajaran saat microteaching } \\
\text { membantu, tetapi objeknya berbeda sehingga ada siswa yang } \\
\text { mengobrol. } \\
\text { c. Penggunaan bahasa juga berpengaruh sedikit karena berasal dari } \\
\text { sunda. Saat penutupan } \\
\text { d. Pembelajaran siswa juga terburu-buru pulang sehingga menjadi } \\
\text { tidak fokus. }\end{array}$ \\
\hline
\end{tabular}


Pengaruh kemampuan disposisi terhadap kemampuan mengajar matematika dalam PPL dapat dilihat pada Tabel 11.

Tabel 11. Hasil Wawancara Pengaruh Kemampuan Disposisi terhadap Kemampuan Mengajar PPL.

\begin{tabular}{|c|c|}
\hline Subjek kelas & Kemampuan Disposisi \\
\hline Atas & $\begin{array}{l}\text { a. Percaya diri membuat mahasiswa dapat menguasai kelas } \\
\text { b. Kegigihan, fleksibel, dan mengaplikasikan matematika } \\
\text { menjadikan mahasiswa selalu ingin mencari ide baru dan } \\
\text { mengakaitkan dengan bidang lain. } \\
\text { c. Merefleksi diri dapat mempengaruhi kinerja mahasiswa menjadi } \\
\text { lebih baik lagi }\end{array}$ \\
\hline Tengah & $\begin{array}{l}\text { a. Percaya diri membuat mahasiswa lebih yakin dan mantap } \\
\text { mengajar } \\
\text { b. Kegigihan, fleksibel, mengaplikasikan matetematika dapat } \\
\text { menjadikan mahasiswa selalu belajar dan membuat pembelajaran } \\
\text { semakin menarik } \\
\text { c. merefleksi diri membuat pembelajaran yang akan datang menjadi } \\
\text { lebih baik. }\end{array}$ \\
\hline Bawah & $\begin{array}{l}\text { a. percaya diri lebih bisa bicara didepan kelas } \\
\text { b. Karena materi yang dituntut untuk diajarkan secara mendadak jadi } \\
\text { berfikir fleksibel dan kegigihan tidak berpengaruh } \\
\text { c. rasa suka, rasa ingin tahu dan minat berpengaruh agar lebih rajin } \\
\text { belajar } \\
\text { d. kemampuan aplikasi matematika terhadap disiplin ilmu lain sedikit } \\
\text { berpengaruh karena tidak terlalu bisa melakukannya. }\end{array}$ \\
\hline
\end{tabular}




\section{KESIMPULAN}

Berdasarkan hasil analisis dan pembahasan pada bab sebelumnya, maka kesimpulan dalam penelitian pengembangan ini adalah sebagai berikut.

1. Ada pengaruh positif prestasi pengajaran mikro terhadap kemampuan mengajar matematika dalam Program Pengalaman Lapangan (PPL).

2. Ada pengaruh positif kemampuan disposisi matematika terhadap kemampuan mengajar matematika dalam Program Pengalaman Lapangan (PPL).

3. Ada pengaruh positif prestasi pengajaran mikro dan kemampuan disposisi matematika terhadap kemampuan mengajar matematika dalam Program Pengalaman Lapangan (PPL).

Hasil wawancara menunjukkan bahwa prestasi pengajaran mikro dan kemampuan disposisi matematika berpengaruh terhadap kemampuan mengajar matematika dalam PPL. Mahasiswa kelas atas menyebutkan bahwa perencanaan, model, dan pengausaan materi saat pengajaran mikro berpengaruh terhadap pembelajaran saat PPL. Kendala yang terjadi adalah pada pembukaan dan pembukaan pembelajaran evaluasi lebih efektif di PPL. Kemampuan disposisi matematika juga berpengaruh dalam menguasai kelas dan mencari ide baru serta megevaluasi diri menjadi lebih baik lagi.

Mahasiswa kelas tengah mengangap perencanaan, model menjadikan pembelajaran saat PPL lebih terstruktur, dan uji coba model untuk PPL. Kendalanya adalah media di sekolah tidak tersedia serta pengajaran microteaching hanya simulasi sehingga keadaan siswa PPL sangat berbeda.

Mahasiswa kelas bawah mengatakan bahwa perencaan saat pengajaran mikro tidak sesuai dengan PPL, saat membuka pembelajaran siswa mengobrol sendiri, akan tetapi penggunaan bahasa berpengaruh. Saat pembelajaran siswa buru buru pulang sehingga kemampuan penutupan saat pengajaran mikro tidak berpengaruh. Percaya diri berpengaruh sehingga bisa bicara di depan kelas, Karena materi yang dituntut untuk diajarkan secara mendadak jadi berfikir fleksibel dan kegigihan tidak berpengaruh, rasa suka, rasa ingin tahu dan minat berpengaruh agar lebih rajin belajar,kemampuan aplikasi matematika tidak terlalu bisa melakukannya. 


\section{DAFTAR PUSTAKA}

Arsito, S. (2014). Analysis Of Relationship Between Micro Teaching Achievement and Teaching English Ability in Apprenticeship. Jurnal Pendidikan Telesari, $4(1)$.

Fadly, A. (2015). Pengaruh Prestasi Belajar Micro Teaching dan Bimbingan Guru Pamong terhadap Kemampuan Mengajar Mahasiswa dalam Program Pengalaman Lapangan (PPL) Prodi Pendidikan Tata Niaga. Medan: Universitas Negeri Medan.

Mahmudi, A. (2010). Tinjauan Asosiasi antara Kemampuan Pemecahan Masalah Matematis dan Disposisi Matematis. Yogyakarta: FMIPA Universitas Negeri Yogyakarta.

Muhidin, S. A. dan Maman A. (2011). Analisis Korelasi, Regresi, dan Jalur dalam Penelitian. Bandung: Pustaka Setia.

National Council of Teacher of Mathematics. (1989). Curriculum and evaluation standard for school mathematics. Reston, VA: Author.

NCATE/NCTM. (2003). Programs for Initial Preparation of Mathematics Teachers. http://www.math.uri.edu/ eaton/ NCATENCTM. pdf (diunduh 20 September 2013).

Ruseffendi, H. (2006). Pengantar Kepada Membantu Guru Mengembangkan Kompetensinya Dalam Pengajaran Matematika Untuk Meningkatkan CBSA. Bandung : PT.Tarsito

Setyaningrum, W. (2009). Pengaruh Pengajaran Micro Teaching dan Bimbingan Guru Pamong terhadap Prestasi PPL Mahasiswa Pendidikan Akuntansi Tahun Ajaran 2008/2009.Surakarta : UMS.

Sofuroh. 2014. Model Learning Cycle 5E Dengan Pendekatan Scientific Untuk Meningkatkan Disposisi Matematis dan Berpikir Kritis. Unnes Journal Of Mathematics Education Research, 3 (2), 91-97.

Sudjana, N. 2005. Metode Statistika. Bandung : PT Tarsito.

Sugiyono. 2010. Statistika untuk Penelitian. Bandung : Alfabeta.

Sugiyono. 2012. Metode Penelitian Kuantitatif kualitatif dan R\&D. Bandung : Alfabeta.

Sukestiyarno,Y. L. 2012b. Olah Data Penelitian Berbantuan SPSS. Semarang: Universitas Negeri Semarang.

Supriatna, D. 2009. "Konsep Dasar Desain Pembelajaran”. Online http://docs.google. com/gview?url=http://www.tkplb.org/documents/etrainingmedia\%20pembelaj aran/3.Konsep_Dasar_Desain_Pembelajaran.pdf.(12 Januari, 2015: 19.14) 